\title{
CREDIBILITY AND MARKETS AS GREENING FORCES FOR THE CHEMICAL INDUSTRY
}

\author{
Johan Schot \\ School of Phllosophy and Social Sciences \\ University of Twente, Netherlands
}

\section{Introduction}

One of the central problems the world currently faces is environmental degradation. Research data have shown that the natural environment is in an alarming state. The production of pollutants emissions and products - and energy consumption needs to be reduced substantially. The role of industry is particulary vital in reaching this goal. Companies need to act in a pro-active and preventive way. There are definite signs of an about-turn in the way the top management of some companies think and act. Many business leaders, especially in the chemical industry, have stated in public that the environmental aspects of management should no longer be regarded as being restrictive to business practice, but as a natural part of their social responsibility to society and even as an opportunity to conquer new markets and to innovate.

The way a business is nu with regard to the environment is, however, still largely a black box. Very little research is carried out into the way in which a company responds to the mounting pressures to prove their faithfulness and how they incorporate environmental aspects in their business strategy. This article reports on a study of the Dutch Chemical Industry with the aim of broadening one's insight as to how company managements act with regard to the environment.

In this study two starting points were taken. First of all firms should not be considered as monolithic blocks. Various actors in a firm conjointly shape company behaviour, including the environmental aspects. It is therefore important to trace strategies of various actors and interactions among actors within the firm. Secondly, following Hakansson (1987), furms cannot be regarded as independent units. There are often intense relationships between intemal and external actors. Accordingly, the border of the company is not a dividing line. In our study we have attempted to investigate the role of environmental aspects in the strategy of a broad variety of actors both inside the company (top management and line management, employees, $R \& D$, marketing, purchasing, environmental, health and safety, quality assurance and financial departments) and outside the company (accountants, banks, assurance companies, trade unions, environmental groups, user firms, suppliers, government.). We have concentrated our research around four themes which mobilise specific coalitions of actors inside and outside the firm: credibility pressures, changing strategies and innovation, pressures from financial actors like bankers and insurance companies, and a changing regulatory environment pressing for more prevention and the institutionalisation of environmental care systems. This paper summarises the results with regard to the themes of credibility, changing strategies and innovation. The study was geared towards multinational companies and small and medium-sized companies. However, this paper will only deal with the results that relate to the multinationals. These results were based not only on literature and company documentation but also on in-depth interviews with officials of eight multinational companies: ICI, DSM, DOW Chemical, Shell, Exxon, DuPont, Hoechst, and Unilever. In addition to interviews with the top managers responsible for matters of the environment in seven of the eight companies interviews were also held with marketing, R\&D, PR and purchasing department managers. We agreed not to make any explicit references to the individual companies in the report itself. Both themes - credibility and changing markets - will be dealt with in this paper on the same lines: a short introduction is followed by a section dealing with the research results. This is followed by a section in which I have formulated several conclusions.

\section{Credibility at Stake}

\subsection{Introduction}

The credibility of the chemical industry has been brought under pressure in recent years. This was the result of incidents that received a large amount of publicity (Bhopal, Sandoz, Valdez) and the emission of substances which give rise to environmental problems on a global scale, i.e. the bole in the ozone layer and the greenhouse effect. The chemical industry itself does not stand alone in 
the direct line of fire because of such accidents and emissions; the products it produces are also beginning to join it (Elkington 1988, p.118). Plastics are a good example in this respect. Consumers have become convinced that plastics are hazardous to both health and the environment and consequently blame the chemical industry. The use of plastic as a packaging material is especially condemned. The main attention-getter at the present time is PVC which, if improperly incinerated, can result in the emission of dioxin. In this section we shall look at what effects have been brought about because of the pressure on credibility and the initiatives that have been taken to communicate with the public in order to restore their lack of faith.

\subsection{Research Results}

\section{The Effect of Pressure on Credibllity}

Our study has shown that company managers are becoming increasingly aware that it is important that their company is regarded as a skilled and trustworthy partner by the general public. Running a company in a way which has a pasitive view towards the environment has become a major element of the corporate image. This applies particularly in the chemical sector.

Even though it is difficult to measure the precise effect of a poor environmental image on a company's profitability there is a perception that such a bad image can have several harmful consequences: a drop in share prices, restless banks and clients, personnel motivation starts to wane and it becomes more and more difficult to attract qualified staff. This will eventually lead to a reduction in turnover and declining profits.

In multinational companies in the chemical industry poor image is therefore one of the main motivations for devoting more attention to the environmental aspects of their activities. Poor image has led to top management becoming more involved with environmental matters. In the companies interviewed this has resulted in a wide range of initiatives taken at top level. These include the formulation of objectives to drastically reduce emissions, the integration of environmental aspects in the development of products, and stringent control on the implementation of their own regulations by carrying out audits. It is also apparent that various departments are able to make particular and successful use of this argument in order to push through their environmental plans; this is particularly the case in environmental and marketing departments. The changes we have mentioned here will also be discussed in the next section. It is quite obvious however that these changes are a direct, and indeed the main result of the pressure that has built up on the aspect of credibility. Below we will go into the communication activities that have been undertaken in an attempt to regain that credibility.

\section{Communication as Reply}

The importance of developing an environmental communication policy is stressed at the corporate level of multinational companies. Top management suggests that in the past the views of the public were not taken seriously enough or not listened to properiy. The industry tended to adopt the view that effects on the environment should first be indisputably proven scientifically. This attitude is now regarded as technocratic.

In the companies we interviewed this has resulted in the development in recent years of communication initiatives at various factory locations. This communication is targeted mainly at those living in the neighbourhood of the plants in question. These communication activities involved the organisation of open days, forums, brochures and press reports. They in turn were given additional weight and dimension through the implementation of the EEC Seveso directive which came into force in 1984. Article eight of this directive states that all persons who could possibly be affected by a critical accident due to industrial activity must be informed in an appropriate manner of the safety measures that have been taken and what action they themselves should take in the event of an accident. Because company managements place their communication activities within the framework of this directive a relatively large amount of attention is given to instructions for emergency situations and much less to emissions for example.

The main objective of such communication is to regain the public's confidence by providing them with information. It is not aimed at fostering a dialogue with those who live in the area and 
environmental pressure groups and/or the involvement of these in the company's environmental policy decision-making process. In some of the interviews it was indicated that this dialogue, and the corresponding involvement of neighbouring residents and pressure groups in their environmental policy, was an attractive proposition but that the industry was not quite ready for such a step.

\section{The Reaction of Neighbouring Residents and the Environmental Movement}

The general public, residents in the neighbourhood and environmentalists have up to now shown little response to the initiatives taken by companies to communicate on aspects concerning the environment. Very few members of the public attend the forums organised within the framework of implementing the Seveso directive. Environmentalists fail to respond to company invitations to visit their plants.

One explanation of this lack of interest is the informative character of these communication activities and invitations. They are not primarily intended to start up a dialogue on decision-making within the company and the invitations are ad hoc. Companies do not pursue a structural policy for the participation of environmental pressure groups in their environmental policy. However, the environmental movement as a whole has little need for direct communication with industry at this point in time. The strategy adopted by the individual pressure groups is to make use of the fact that companies are extremely sensitive to publicity and thus able to exert pressure on management with a view to the company's credibility. These campaigns are generally nation wide and/or aimed at specific companies and/or products (cadmium in beer crates, PVC, phosphates, etc.). This strategy has been successful to date, hence the reason why there is little need for direct communication and negotiations on a structural basis. Environmental pressure groups do not regard the trend of companies to improve their communication activities as a reason to enter into direct discussion with industry. More openness is welcomed, but mainly because it increases the possibilities for social control. Pressure groups are then more able to challenge companies on their polluting activities via the courts.

\section{Registration of Emissions and Environmental Accounts}

In their communications most companies are reticent to disclose figures on their emissions as this could form a breach of secrecy. Nor are separate environmental reports published wo supplement annual social and financial reports. Most multinationals do however draw up environmental reports for internal use only. Although these are not made public, in some cases they are used as documentation in the discussions that have to take place before the relevant authorities grant licences. There is no legislation which makes provision for the mandatory publication of emission figures and/or environmental reports. Consequently the effect this would have on how companics would act in the interest of the environment is unknown.

\subsection{Discussion}

Our study shows that the risk of damaging the company's image is one of the main driving forces for multinational companies in the chemical industry to bring about change (see also Baram et al. 1990). It has led to top management being strongly committed to the environment, and various measures have indeed been taken to improve the quality of environmental management. In this context we can mention the formulation of objectives to drastically reduce emissions and the integration of environmental objectives in the product policy.

Pressure on credibility, in addition to improving environmental management, has mainly led to a higher level of communication directed to the public with the objective of regaining the public's faith in the company. Quite definite statements are made at corporate level to the effect that the general public should no longer be regarded as ignorant outsiders who are betuer ignored. On the contrary, attention should be given to the demands, wishes and views held by the general public.

Concrete communication initiatives are undertaken at location level targeted towards those who live in the immediate vicinity of the relevant plant. However, these initiatives are in the form of information and not dialogue. There is an enormous reticence to publish environmental reports and emission figures. Making company information public tends to give certain people cold feet. 
The enormous reticence with regard to making certain information public and the limitations of concrete communication initiatives starkly contrasts against the statements made by top management on the importance of communicating with the public. These statements emphasise the significance of direct active dialogue with the public. Very little of this is reflected in the policy pursued. We also note a certain tension between the industry's call for more responsibility for their own actions and the refusal to couple this with a higher level of openness. And yet we must not see this as a standstill. It is quite clear from our study - and indeed studies carried out elsewhere - that there is a growing willingness in the chemical industry to start up such active dialogue.

\section{Changing Markets and Company Strategy}

\subsection{Introduction}

Relatively little has been done in the past to prevent pollution in the environmental policies of companies in the chemical industry. Reduction of emissions through the application of purification technologies has had the upper-hand above measures for the modification of product and process and measures to facilitate re-use. Prevention requires the integration of environmental criteria in the strategic market policy pursued by a company. The question we are most concerned with here however is to what extent have the managers of companies started to give more consideration to the environmental aspects of their products and processes when determining strategy.

In large multinationals the determination of strategy is a very complex process and involves various levels. Initiatives taken by the board of directors, the strategies of product groups and R\&D strategy all have to be examined. For the development of ecologically sound products and processes a call is often made on the expertise of the suppliers. This is the reason why the role played by environmental aspects in the relation between users and suppliers will also become involved.

\subsection{Research Results}

\section{Top Management Initiatives}

In recent years the top managers of large multinational companies have started to implement initiatives to improve the company's environmental policy. The boards of directors of the companies we interviewed had undertaken the following activities:

* The drawing up of new statements on environmental policy, or a further specification of existing ones. Companies promise to play a leading role in reducing emissions beyond compliance, assigning responsibility to specific actors within the firm, like R\&D and the line organisation, and requiring specific practices, for instance audits.

* The tightening up of the internal enforcement programme. A wide range of initiatives are taken, such as the development of strict guidelines, external audits initiated by the board of directors, and the development of improved measuring and registration procedures in order to be able to map out environmental performance at the various locations.

* The formulation of objectives to substantially reduce emissions. These objectives can relate to specific problematic substances (e.g. CFC's or heavy metals in pigments) or the reduction of waste and emissions into soil, air and water. These objectives are formulated in terms of reduction percentages in relation to a time path. For example solid waste must be reduced by $50 \%$ within five years. In order to realise these substantial reduction objectives a relatively large amount of attention is given to the potentials of a preventive and source-oriented policy. An attempt is also made to avoid environmental problems being shifted from one compartment to the other (soil, water, air). For a preventive source-oriented policy it is essential that the individual flows of waste are made perceptible by developing drastic measuring and registration procedures.

All these initiatives were to a greater or lesser extent evident in all eight companies interviewed. They have mainly resulted in the reduction of chemical substance emissions through good housekeeping, separation of waste - making internal or external re-use possible, improvements in purification technology and process modification. More fundamental product changes, and the 
corresponding process modifications, form a part of product group strategy-determination, and will be discussed below.

\section{The Environmental Strategles of Product Groups}

The trend in recent years is for product groups to take environmental aspects into account in their strategic policy for the development of new products and the management of existing ones. The mast far-reaching activity we noted during our study was an initiative put forward by the board of directors that all product groups should systematically draw up a list of the likelihoods and threats of environmental policy for the various product/market combinations. Although the outcome of this is unknown as yet it is expected that by using these lists specific market niches will be able to be defined and thus allow the development of products bearing certain environmental characteristics. The general trend we noted during our investigations was far less radical. Similar inventories are only carried out in the other seven companies on an ad hoc basis for specific product/market combinations faced with problems because of external developments.

We noted that the following strategies were employed in the development of new products:

* 'Backing two horses at the same time strategy'. When taking this approach a search is made for a more fundamental product modification to resolve a specific environmental problem while also looking for a relatively easy short-term modification of the existing product. The strategy aims at keeping the short-term benefits of an existing product for which there is a stabilised market. At the same time one hopes to avoid a situation where no alternatives are at hand should the market for the old product collapse. An example of this is ICI's use of biotechnology to search in the short term for crops which are resistant to pesticides. This allows its pesticide division to continue producing pesticides. It is acknowledged that in the long term the most feasible path to take is the genetic manipulation of crops to make them disease resistant. This would do away with the need for pesticides. Research into this is under way. A second example is that the plastics industry is searching on the one hand to improve oil-based plastics and make them more suitable for re-use, while at the same time it is looking in the long term for radical, non oil-based alternatives which are biodegradable. The application of this strategy implies that the long-term solution would only be implemented if the short-term solution no longer works or if the introduction of the new product would achieve an advantage over the competition. Until then, the continuing objective is to bring in as much money as possible from the existing product The long-term solution is consciously kept at the laboratory stage.

* Diversification strategy. This is a variation on the theme of backing two horses at the same time. A more ecologically sound altemative product is developed but is priced so high that it cannot possible compete against the far cheaper, existing product Two separate markets are thus created. The company is thus able to continue selling its existing, polluting product while at the same time opening up a new market for the more ecologically sound alternative. The likelihood is that the total share of the market will increase.

* Re-use strategy. There is a strong tendency in the industry to give preference to re-use rather than to the development of alternative products. Consequently, it concentrates on waste management One example is PVC: plastics manufacturers are aiming at re-use and channel their research and development in this direction. Preference for this strategy is quite obvious as it does not immediately endanger existing market shares.

These strategies express the general expectations held in the companies interviewed, namely that the existing production patterns will continue as they are for the shorter term of 10 to 20 years. Companies will integrate environmental aspects into their policies, but only by adding these aspects to the standard requirements of quality applying to all products. Companies are not pressing substitution of existing products (see also Rappaport et al. 1991).

\section{Management Structures and Recruitment}

Over the past few years environmental aspects involved in the running of a business have been high on the agenda of top management on a more or less daily basis. Environmental aspects have 
consequently become a more-or-less routine component of policy. This applies to all layers of top management: the board of directors; the product groups; and the factories. Some companies have chosen to give a single person on the board of directors or management the responsibility for aspects of the environment and safety. ICI and Union Carbide have appointed separate Safety, Health and Environment (SHE) managers in the directorate of a product division. These are given the power of veto. Other companies consciously reject this, putting forward the argument that environmental aspects must be included in all manager's policies and should not be isolated by giving the responsibility to one person only.

However, experience on aspects of environment and safety have no role to play in the recruitment of top managers. Environment and safety officers usually find themselves in a job which offers no further prospects and where there is no systematic circulation of staff. This simation reflects that specialist environmental managers are given the main task of establishing the company's environmental policy with regard to emissions and accidents, and to maintain contacts with regulatory agencies (see ECOTEC 1990). At the same time managers in more general fields are given the additional task of integrating environmental aspects with the company's strategy. Specialist environmental managers have little direct contact, if any, with the strategic decision-making process in the product divisions. These often deal primarily with the operating companies at the various locations. There are indications that this situation will change, and that more formal channels will be opened through which the environmental staff can directly influence the innovation and strategic decision-making process (see for instance Groenewegen and Vergragt 1991).

\section{R\&D and the Environment}

The work of R\&D departments is $80 \%$ to $90 \%$ work which is assigned and paid for by the product groups. Only a small percentage of the funds is available for independent research, and the direction this should take is determined by the board of directors. The objectives of R\&D departments are therefore largely linked to the strategy of the product group. Both R\&D department and product group discuss the actual significance of that link. Our study shows that in the companies we interviewed no routine attention is given to the environmental aspect in the discussions on $R \& D$ to arise - with regard to certain products of that product group as a result of external developments. In a few of the companies we visited the board of directors had initiated environmental projects on an ad hoc basis within the scope allowed. But the general line is still one whereby no explicit, outside initiated environmental objectives are incorporated in $R \& D$ planning. Nor is any systematic attempt made in R\&D departments to select new projects from the angle of environmental objectives. There are hardly any initiatives aiming at incorporating environmental objectives in R\&D culture. Yet there are various means that could in principle be applied to achieve this: provision of information for instance, training courses or awarding a prize for environmental innovation (see Twiss 1980). In several of the interviews it was expressed, however, that aspects of the environment would start to play a more dominant role in the structure and culture of R\&D in the near future.

In all eight companies once a project has been chosen procedures come into motion in which the project, even in the early phase of its development, is screened for its potential effects on the environment. Special committees are often set up for this purpose and they carry a great deal of weight. They can block the development of a product. Environmental requirements are included in the design when developing plants (processes). Various check-list procedures with regard to environmental effects are implemented in order to check plant development in the various scaling-up stages.

\section{Environmental Co-Makership}

To develop ecologically sound products all possible effects on the environment that could occur during the entire life-cycle of the relevant products must be looked into. Given that companies are not generally involved in each and every phase of that life-cycle it is therefore essential to have some form of interaction between different companies.

Our investigations showed that two forms of interaction are practised between companies:

* Users request information about environmental aspects from their suppliers.

* Users set demands to be met by their suppliers with regard to environmental aspects. 
Both forms of interaction could lead to the development of environmental friendly products and practices.

Present developments are still ad hoc. These companies do not pursue a purchasing policy whereby requests for information on environmental aspects or stipulations with regard to environmental aspects are made as a matter of routine.

Information requested about environmental aspects relates to such matters as: the environmental characteristics of the relevant products in the waste stage, recycling possibilities, and emissions that occur during production at the suppliers. One of the eight companies reacted to user queries by designing Environmental Data Sheets, similar to Material Data Sheets. This makes it possible to supply the requested information in a systematic and standardised manner. Several of the other companies anticipated that within the next five years a trend would clearly emerge whereby suppliers would be required to furnish details about the environmental aspects of the products supplied as a standard part of the delivery contract. This could be in the form of the foregoing Environmental Data Sheets.

The kind of stipulations users require their suppliers to meet with regard to environmental aspects are:

* Requirements pertaining to substances which, from the point of view of environmental protection, are considered problematic or which receive a great deal of publicity. Companies consequently request their suppliers to supply the product without that particular substance. Examples of such substances are PVC, cadmium and CFC's (see Cramer et al 1991 also).

* Requirements with the objective of increasing the possibilities for the re-use of ones own product at the waste stage. The motorcar industry is looking into ways of recovering the plastics used in cars when they are ready for scrap. One condition here, however, is that all the plastics used have the same molecular structure. If this is the case then it is much easier to recycle and re-use these plastics. The motorcar industry subsequently exerts pressure on the chemical industry to supply plastics which meet these demands for re-use. Various companies are also investigating methods to increase re-use of their own packaging materials. For instance, investigations are being carried out into the possibilities of returnable butter floats or detergent containers.

* Specification as to method of delivery. Waste is becoming an increasingly heavy expenditure item and its storage involves risk. It is for this reason that an increasing number of companies are turning to the implementation of a surict policy on stock. The objective is to keep the amount of stock as low as passible. Suppliers are requested to deliver the exact amount required, preferably in returnable packaging; they are also requested to forward the order so that it arrives on the day it is required for use. This is line with the general trend of avoiding building-up stock and just-in-time delivery (see Hunter 1989).

Manufacturers of end products have not yet reached the stage of using checklists as a standard practice which contain the specifications to which the products of suppliers must comply. Nor are any requirements specified for the supplier's environmental care system. Nevertheless, during the interviews several people expressed that for both cases it was generally expected that this would be the case in the future. Two arguments are given for this. In the first place it is impossible for an end-user to sell his product as ecologically sound if the raw materials used in that product are produced in such a way that they have an extremely adverse effect on the environment. Secondly, experiences with quality care are also pointed out. Originally, users mainly set requirements on the product's quality. In recent years however requirements have started to be imposed on the process and system used in the manufacture of that product.

There are three main motives why users set environmental requirements to be met by their suppliers:

i) reduction in cost

ii) shifting the responsibility for consequences of regulations

iii) anticipating or reacting to market demands. 
Four problems or barriers standing in the way of setting requirements to be met by suppliers were brought up by the companies we interviewed:

* there is a risk that those contracting work out will be held responsible for the conduct of their suppliers;

* setting environmental requirements is the responsibility of suppliers;

* some suppliers hold such a market position that the user is unable to ignore them. There is insufficient latitude to be able to set demands;

* setting requirements implies that the characteristics of the product to be supplied change. This can have an effect on the user's production process. The user must then be prepared to relate his own environmental requirements to other quality requirements.

Environmental $\infty$-makership has been described above in terms of users requesting information or setting requirements to be met by suppliers. Yet in the majority of cases it is not so that the users exert pressure on suppliers unilaterally. It is more a question of a consultation process which sometimes even results in a joint study in order to search for a solution or leads to the joint setting up of a new company. Therefore, I would like to give both forms of interaction the label environmental co-makership.

\subsection{Discussion}

The economic goals of multinationals are concerned mainly with profit and continuity; profits serving mainly as the means to secure income and safeguard investments. This makes it possible for the company to remain active in the constant competitive struggle and to be able to always adapt to changes in their surroundings. It is not surprising to see that one of the main tasks of management is to make a careful study and analysis of the changes that take place in the immediate surroundings and incorporate the results in policy. Environmental aspects are becoming progressively more dominant in company surroundings. The environmental characteristics of products are becoming more important in the market, regulations are being tightened up and there is a growing pressure on credibility. All of these trends would appear to be irreversible. Companies can defend themselves against these changes in their surroundings through their strategic policy. It is pertinent to distinguish between five different kinds of strategy: dependent, defensive, offensive, innovative and niche strategy.

If a company adopts a dependent strategy it has little policy of its own to pursue with regard to the reduction of emission levels. An attempt is made to comply with the licence requirements but this is not high on the list of priorities. Generally speaking, the measures are simply taken as they are set out by the body that issues the licence. Very few measuring instruments are used to find out how far one keeps within the limits set out in the licence. Top management is not committed to environmental policy.

Pursuing a defensive strategy implies that a company does its best to comply with the regulations set by government. This can be coupled with substantial investments in order to achieve the required emission reductions. Solutions are sought mainly in technology and not in organisation. While top management has a definite commitment to see that the company's activities are ecologically sound the environmental problems are solved at local level by the factories themselves in consultation with environmental managers appointed for that specific purpose and the relevant authority (council, provincial or national government). Very little thought is given to the aspect of prevention. Environmental aspects therefore have no role in the strategy network. Environmental problems are defined as external problems and are seen as a restriction on company conduct.

In the case of an offensive strategy environmental problems are regarded specifically as problems for which the company itself will have to find a solution. The company pursues its own policy to achieve a substantial reduction in the level of its emissions, sometimes to levels far below the levels stipulated in government regulations. Solutions are looked for in the organisational sphere as well as in the realms of technology. A great deal of importance is therefore attached to the setting up of an environmental care system. Attention is also given to preventive process solutions (e.g. optimising the utilisation of raw materials and good housekeeping) and thus tackling the emission problem at 
source. Top management plays the active role of stimulating the search for solutions and making sure that both internal and external regulations are observed. Finally, environmental aspects also play a role in the strategy network, but then mainly in a negative sense. In other words an attempt is made to detect and eliminate the market risks involved for products because of specific environmental characteristics. Solutions to eliminate these risks are sought primarily in improving and modifying existing products so that, for example, re-use becomes a possibility. Environmental characteristics are added to a whole range of existing criteria and this determines the quality of the product. Simultaneously, experiments are carried out at laboratory level on radically new products which could make existing products utterly superfluous. The objective is to have an alternative at hand in case the existing product should be taken off the market sooner than expected due, for instance, to more stringent regulations or the introduction of an alternative by the competition. These alternatives are not pushed all that strongly but are consciously kept at the laboratory stage.

Innovative strategy is based on the expectation that in time excelling in the field of the environment can lead to enormous competitive advantages. This strategy is aimed at increasing the company's ability to innovate in such an ecologically sound way that radical product innovations are provoked. This ability to innovate in an coologically sound way is increased by:

* formulating an explicit strategic view towards the environment by the board of directors and other central actors in the strategic network, such as product groups, R\&D and marketing departments;

* expanding the knowledge base in R\&D departments, marketing departments and product groups with essential environmental knowledge, and establishing contact with universities;

* creating organisational conditions for synergy in the field of the environment between all actors in the strategic network both inside and outside the company (clients and suppliers). Feedback and learning processes between these actors are essential in creating synergy.

The niche strategy is aimed at finding a niche in the market - as quickly as possible and without the need for too great a research effort - for which an ecologically-sound product can be made.

The majority of multinational companies find themselves in a transition period, shifting from a defensive strategy to an offensive strategy. There is an awareness that the industry will need to react and anticipate the increasing importance of the environmental aspects of products and processes. The willingness to go much further then ever before is prevalent. More thought is being given to prevention. The environmental aspects of both product and process are prerequisite for R\&D policy. R\&D activities are systematically checked against the environmental effects. Moreover, verification afterwards - as opposed to checks beforehand - has the advantage that when products or processes are being developed they are done so with the verification procedure ahead in mind.

The period of transition is characterised by ad hoc policy. In other words, a very conscious choice and implementation of an offensive strategy is out of the question in the majority of cases. Various elements of the defensive, offensive and niche strategy, and sometimes even innovative strategy, are seen in combination. During our intervicws we also noted that there is little or no need felt for the development of a consistent innovative strategy. The introduction of radical, ecologically sound products is not seen as an essential condition for entrepreneurial success in the future. No radical changes are anticipated for existing products and consumer patterns within a period of ten to fifteen years to the effect that companies would be forced to follow a more radical strategy.

\section{References}

1. Baram, M.S., Dillon P.S. and Ruffe, B., (1990) Managing Chemical Risks: Corporate Response to SARA Title III, Medford: The Centre for Environmental Management, Tufts University.

2. Cramer, J., Dral, P. and Roes, B., (1991) 'Environmental Product Profiles for Manufacturers in the Netherlands', Journal of Clean Technologies and Environmental Sciences, Vol.1, No.2, pp.1-10.

3. Cramer, J., Schot, J., van den Akker, F., and Maas Geesteranus, G., (1990) 'Stimulating Clean Technologies through Economic Instruments: Possibilities and Constraints', UNEP 
Industry and Environment, April-May-June, pp.46-53.

4. ECOTEC, (1990) The Impact of Environmental Management on Skills and Jobs, Birmingham.

5. Elkington, J., (1987) The Green Capitalists: Industry's Search for Environmental Excellence, London: Victor Gollancz Lid.

6. Hakkansson, H., (ed.), (1987) Industrial Technological Development: A Network Approach, Croom Helm Publisher London.

7. Groenewegen, P. and Vergragt P. ( ) 'Environmental Issues as Threats and Opportumities for Technological Innovation', Technology Analysis \& Strategic Management, Vol.3, No.1, pp.43-55.

8. Hunter, J., (1989) 'Waste Minimisation through Inventory Control', Paper presented at the Waste Minimisation Conference, May 10, New Brunswick, New Jersey.

9. Petulla, J., (1987) 'Environmental Management in Industry', Journal of Professional Issues in Engineering, Vol.113, No.2, pp.167-183.

10. Rappaport, A., Taylor, G., Flaherty, M. and Pomeroy, G., (1991) 'Global Corporate Environment, Health, and Safety Programs: Management Principles and Practices', Report of The Centre for Environmental Management, Tufts University.

11. Schot, J., (1992), Constructive Technology Assessment and Technology Dynamics: The Case of Clean Technologies, Science, Technology and Human Values, Vol.17, No.1, pp.36-57.

12. Steger, U., (1988) Umweltmanagement; Erfahrungen und Instrumente Einer Umweltorientierten Unternehmensstrategie, Wiesbaden: Frankfurter Allgemeine/Gabler.

13. Twiss, B.C., (1980) Managing Technological Innovation, 2nd ed. London/New York: Longman. 